\title{
IMAGING STUDY OF SPHENOID SINUS AND ANATOMICAL VARIATIONS OF THE NEUROVASCULAR RELATED STRUCTURES
}

\author{
By
}

\author{
Mohamed A. El-Zanfaly, Ahmed M. Khalefa, Adel A. Omar, Mokhtar R. \\ Ramadan*, Ayman A. El-Shahaly and Yehia M. Dawood
}

Departments of Otorhinolaryngology and Radiodiagnosis*, Faculty of Medicine, Al-Azhar University

Corresponding author: Mohamed A. El-Zanfaly,

E-mail: mohamed_elzanfaly2011@gmail.com

\begin{abstract}
Background: Sphenoid sinus is surrounded by several important structures. Sphenoid sinuses are the most inaccessible paranasal sinuses and are surrounded by significant anatomical structures such as the orbit and its contents, cavernous sinus and internal carotid artery (ICA), and the anterior cranial fossa. The different routes to the sella include transethmoidal, transnasal, trans-septal, whether microscopic or endoscopic; ultimately pass through the sphenoid sinus to reach the sella. Complications such as arterial hemorrhage, visual loss, and extra-ocular palsies occurring in the course of endoscopic sinus surgeries or transsphenoidal pituitary procedures can be attributed to the proximity of carotid artery and cranial nerves to the sphenoid sinus.
\end{abstract}

Objective: To study the important structures in the sphenoid sinus and find anatomical variations to guide otorhinolaryngologists to avoid injury of the vital structures during their procedures.

Patients and methods: This study comprised 100 patients complaining of sinonasal attending ENT Department at Al-Azhar University Hospital (Cairo) from October 2018 to October 2020. All patients were subjected to full history taking, clinical and endoscopic examinations, CT scan and MRI.

Results: We found pneumatization of pterygoid process (PP), anterior clinoid process (ACP) and greater wing of sphenoid (GWS) in 30\%, 16\% and 30\% of patients. We found protrusion of anterior clinoid process (ACP), optic nerve (ON), maxillary nerve (MN) and vidian nerve (VN) in $40 \%, 36 \%, 25 \%$ and $28 \%$ of patients and dehiscence of them in $30 \%, 31 \%, 14 \%$ and $37 \%$ of patients. There was a significant association between ACP pneumatization and ICA protrusion, ACP pneumatization and ON protrusion, PP pneumatization and VN protrusion, and GWS pneumatization and MN protrusion. There were significant associations between GWS pneumatization and MN protrusion and between PP pneumatization and VN protrusion.

Conclusion: Coronal CT screening should be used in the pre-surgical evaluation of patients under consideration of endoscopic sphenoid sinus surgery to minimize perioperative neural and vascular injury.

Keywords: Sphenoid sinus, Chronic Hepatitis C, Direct Acting Antivirals.

\section{INTRODUCTION}

The sphenoid sinuses are located at the skull base at the junction of the anterior and middle cerebral fossae. The relationship between the optic nerve and the paranasal sinuses has been studied for nearly a century (Kim et al., 2010). 
It was delineated that the precise relationship between the optic nerves and the posterior paranasal sinuses using CT imaging data, and to determine the relative frequency of variations in this relationship. They concluded that all 300 nerves evaluated in this study were intimately related to the sphenoidal sinus. Only a small minority (3\%) were in contact with the posterior ethmoidal sinus. Coronal CT revealed this relationship and axial scans facilitated visualization of the sphenoethmoidal boundary. They found that increased sphenoidal sinus pneumatization is associated with increasing optic nerve exposure. Anatomic configurations that predispose the optic nerve to injury include the type 2 or type 3 optic nerve relationships, bone dehiscence over the nerve, and pneumatization of the anterior clinoid process. A pneumatized anterior clinoid process is an important indicator of optic nerve vulnerability resulting from the frequent association with both dehiscence and the type 2 or type 3 nerve configurations (DeLano et al., 2010).

Sphenoid sinuses are the most inaccessible paranasal si-nuses and are surrounded by significant anatomical struc-tures such as the orbit and its contents, cavernous sinus and ICA and the anterior cranial fossa. Only thin plates of bones separate these structures from the sphenoid sinus. Pneumatisation of these irregular cavities ranged from their absence to extensive (Davoodi et al., 2011).

The incidence of the different anatomical variations of the sphenoid sinus those are relevant to trans-sphenoid pituitary surgery. ICA produced a definite bulge in the supero-lateral wall of the sinus in $10(50 \%)$ patients, of which 3 (15\%) were bilateral, $6(30 \%)$ were left sided, and one on right side. A definite dehiscence of the bony wall was seen in 9 (45\%) cases, of which $3(15 \%)$ were bilateral, $6(30 \%)$ were on the left and one on the right (Mamatha et al., 2010).

Sella turcica resembles as saddle-like depression, which provide place for the pituitary gland. Anatomically, the sella turcica has been expressed as variable. It is divided into three fragments and consists of an anterior wall, a floor, and a posterior wall. The posterior surface of attached with membrane, which is termed as dorsum sellae and the anterior order is attached with the tuberculum sellae. The whole sellar area is made up of optic chiasma, pituitary gland, internal carotids, cavernous sinus, cranial nerves and sphenoid sinuses (Tekiner et al., 2015).

The association between anomalies in the sphenoid sinus area in paranasal sinuses computed tomography (PNS-CT) and pathological findings. As sphenoid sinus pneumatization increased, the projection of neighbouring vein and nerve structures into the sinus was found to increase as well (Turkdogan et al., 2017).

The aim of this study was to study the important structures in the sphenoid sinus and find anatomical variations in this area to guide otorhinolaryngologist and neurosurgeons to avoid injury of the vital structures during their procedures aiming to safe and complete eradication of the pathology. 


\section{PATIENTS AND METHODS}

This study comprised 100 patients complaining of sinonasal manifestations (headache, nasal obstruction and nasal discharge) attending ENT Department at Al-Azhar University Hospital (Cairo) from October 2018 to October 2020.

We excluded patients with prior sinus surgery, neoplastic sinonasal tumors, nasal polyposis, severe cervical arthropathy, or head or neck injury.

\section{Methods:}

- History taken from every patient.

- Clinical examination including head and neck examination and full ENT examination.

- Endoscopic examination.

- Imaging studies in the form of:

- CT scan (coronal and axial) without contrast.

- Unsatisfactory imaging needs further imaging (CT with contrast and MRI).

Choosing to scan only in the coronal plan reduces the radiation dose to the patient. Each patient was positioned prone with the head hyper-extended on the scanner bed. The scanner gantry was angled perpendicularly to the hard palate. Contiguous slice CT technique was used with 4-mm section thickness from anterior frontal sinus to anterior sphenoid sinus. To obtain proper evaluation of the neighboring structures and their relation to the sphenoid sinus, 2-mm contiguous slice thickness was used from anterior to posterior sphenoid sinus. For visualization of the complex anatomy of this region, imaging is best centered to the nasal cavity and paranasal sinuses. In all the patients, the existence of the following variants was investigated: pneumatization of pterygoid process (PP), anterior clinoid process (ACP), and greater wing of sphenoid (GWS, i.e. floor of middle cranial fossa), protrusion of internal carotid artery (ICA), optic nerve (ON), maxillary nerve $(\mathrm{MN})$, and vidian nerve $(\mathrm{VN})$, and dehiscence of the walls of ICA, $\mathrm{ON}, \mathrm{MN}$, and $\mathrm{VN}$.

Dehiscence is defined as absence of visible bone density separating the sinus from the course of the concerned structure. Whenever a clear decision between "very thin bony wall" and "total dehiscence" was not feasible, the results were accepted as dehiscence. Protrusion of ICA and ON was determined by finding any degree of protrusion of the structure into the sinus cavity. We are unaware of any published criteria for protrusion of $\mathrm{MN}$ and $\mathrm{VN}$, and presence of air density around these structures is accepted as a clue for the protrusion of $\mathrm{MN}$ and $\mathrm{VN}$, at least in a section of coronal investigation. PP pneumatization is recognized if it extends beyond a horizontal plane crossing the vidian canal. Likewise, we define GWS pneumatization when it extends beyond a vertical plane crossing the maxillary canal.

\section{Statistical analysis:}

All statistical analyses were done by using SPSS v23 statistical software (SPSS, Inc, Chicago, Illinois). Data were presented as frequency and percentage and correlation coefficient for qualitative variables. To find the association, Chisquared test was used, $\mathrm{p}<0.05$ was considered statistically significant. 


\section{RESULTS}

Pneumatization of pterygoid process (PP), anterior clinoid process (ACP) and greater wing of sphenoid (GWS) were seen in 30 patients (30\%), 16 patients $(16 \%)$ and 21 patients $(21 \%)$ of patients respectively (Figure 1).

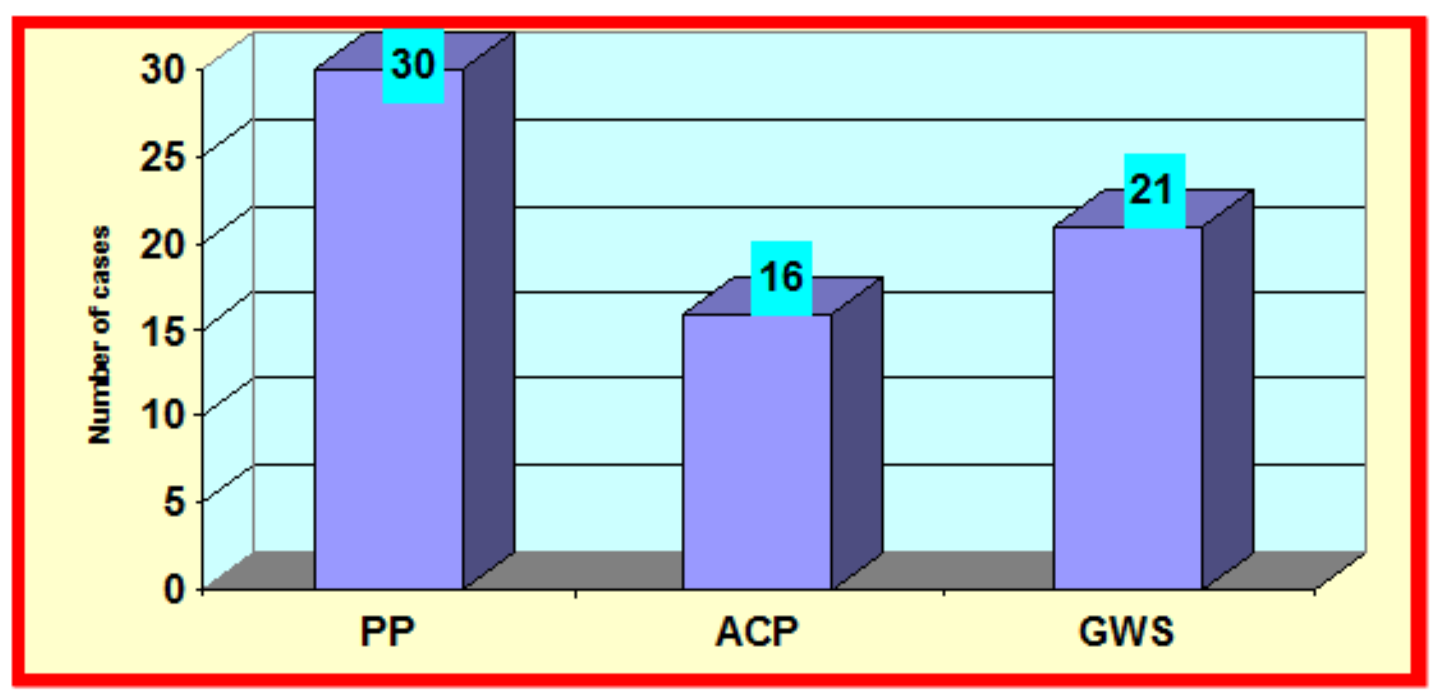

Figure (1): Pneumatization.

Protrusion of internal carotid artery (ICA), optic nerve (ON), maxillary nerve $(\mathrm{MN})$ and vidian nerve $(\mathrm{VN})$ were observed in 40 patients (40\%), 36 patients (36\%), 25 patients (25\%) and 28 patients (28\%) respectively (Figure 2).

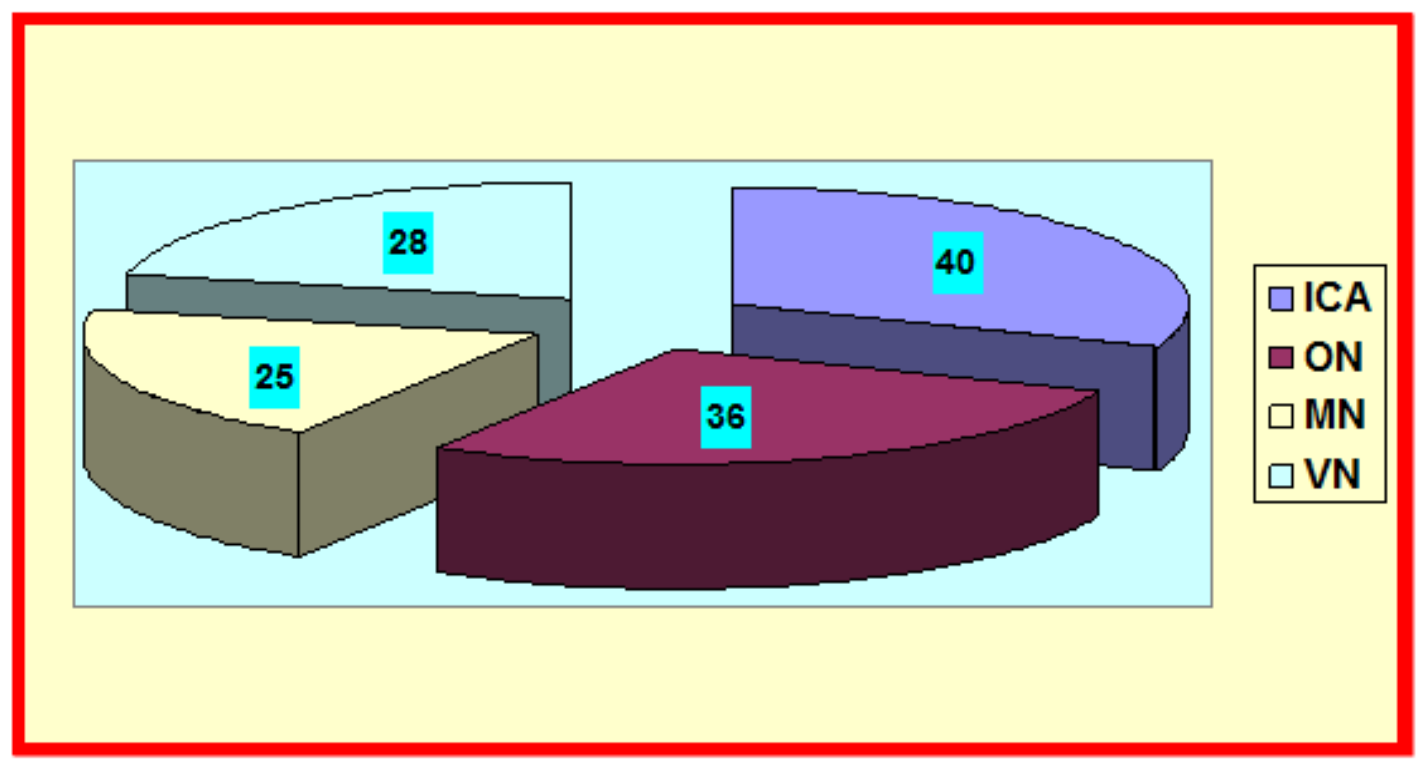

Figure (2): Protrusion 
Dehiscence of the bony wall of the internal carotid artery (ICA), the bony wall of the optic nerve $(\mathrm{ON})$, the bondy wall of the maxillary nerve (MN) and the bony wall of the vidien nerve (VN) was encountered in 30 patients $(30 \%), 31$ patients $(31 \%), 14$ patients $(14 \%)$ and 37 patients (37\%) respectively (Figure 3).

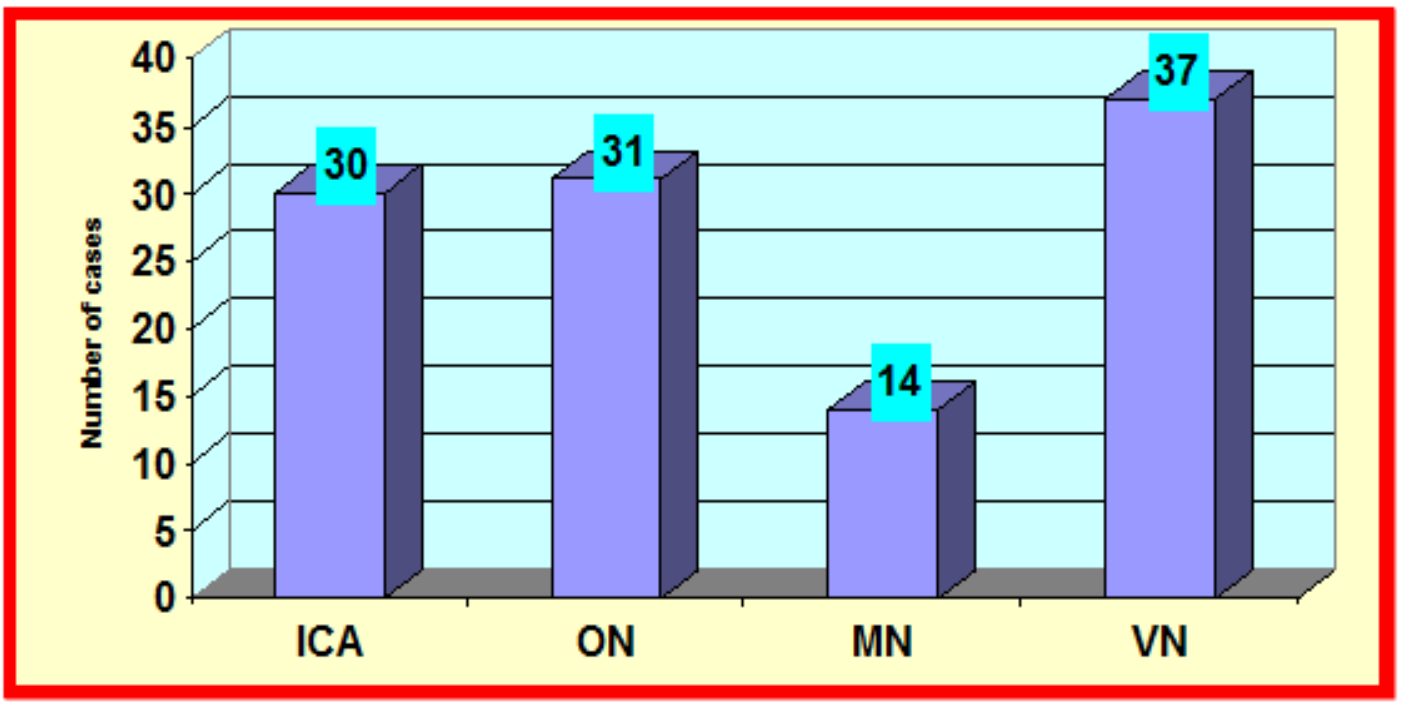

Figure (3): Dehiscence

There were high significant associations between PP pneumatization and ICA protrusion and between $\mathrm{PP}$ neumatization and VN protrusion ( $\mathrm{p}<$ 0.001). There were high significant associations between ACP pneumatization and ICA protrusion and between ACP pneumatization and $\mathrm{ON}$ protrusion $(\mathrm{p}<$ 0.001). There was a high significant association between GWS pneumatization and MN protrusion ( $\mathrm{p}<0.001)$ (Table 1).

Table (1): The relation between pneumatization (PP), ACP \& GWS and protrusion

\begin{tabular}{|c|c|c|c|}
\hline \multicolumn{1}{|c|}{ Protrusion } & Parameters & No & \% \\
\hline \multirow{4}{*}{ PP } & ICA (n= 40) & 14 & 35 \\
& ON (n= 36) & 2 & 5.6 \\
& MN (n= 25) & 2 & 8 \\
& VN (n= 28) & 12 & 42.8 \\
\hline \multirow{4}{*}{ ACP } & ICA (n= 40) & 8 & 20 \\
& ON (n= 36) & 7 & 19.4 \\
& MN (n= 25) & 1 & 4 \\
& VN (n= 28) & 0 & 0 \\
\hline \multirow{3}{*}{ GWS } & ICA (n= 40) & 3 & 7.5 \\
& ON (n= 36) & 3 & 7.5 \\
& MN (n= 25) & 13 & 8.3 \\
& VN (n= 28) & 2 & 7.1 \\
\hline
\end{tabular}




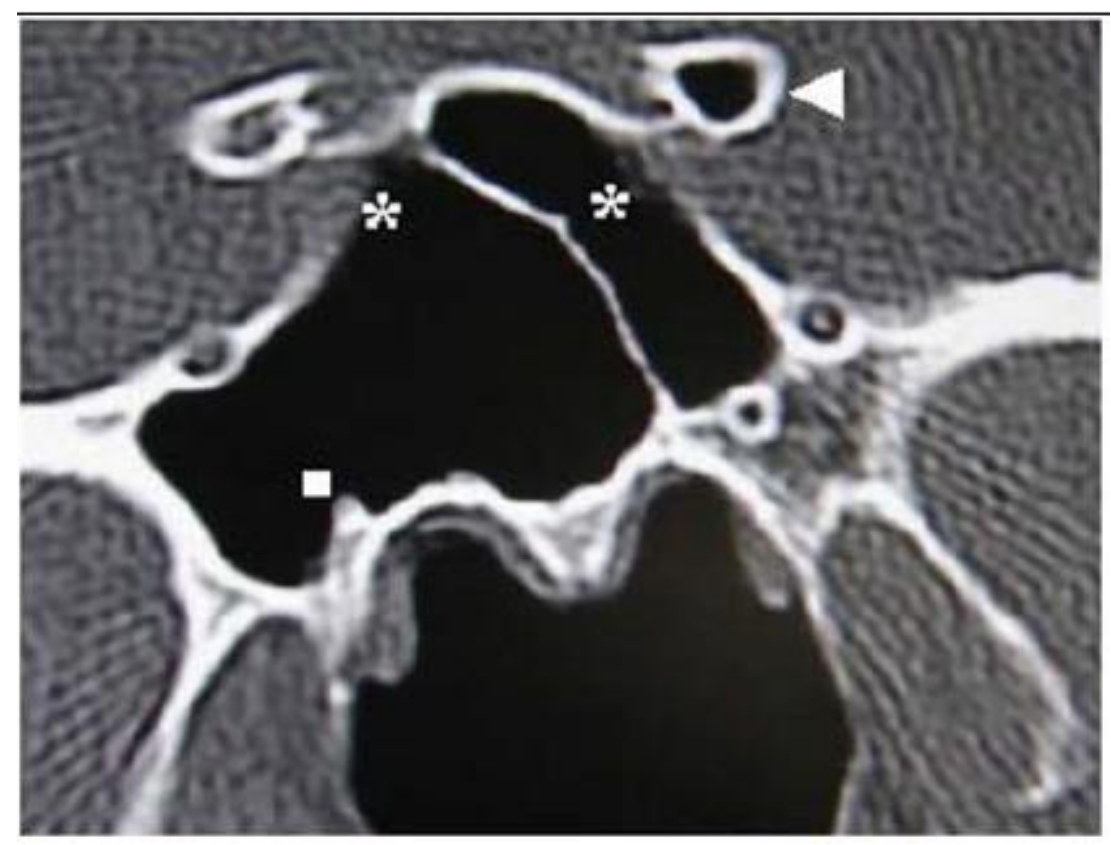

Figure (4): Coronal CT image showing dehiscence of internal carotid arteries (asterisks), pneumatization of left anterior clinoid process (arrowhead), and protrusion and dehiscence of right vidian canal (square)

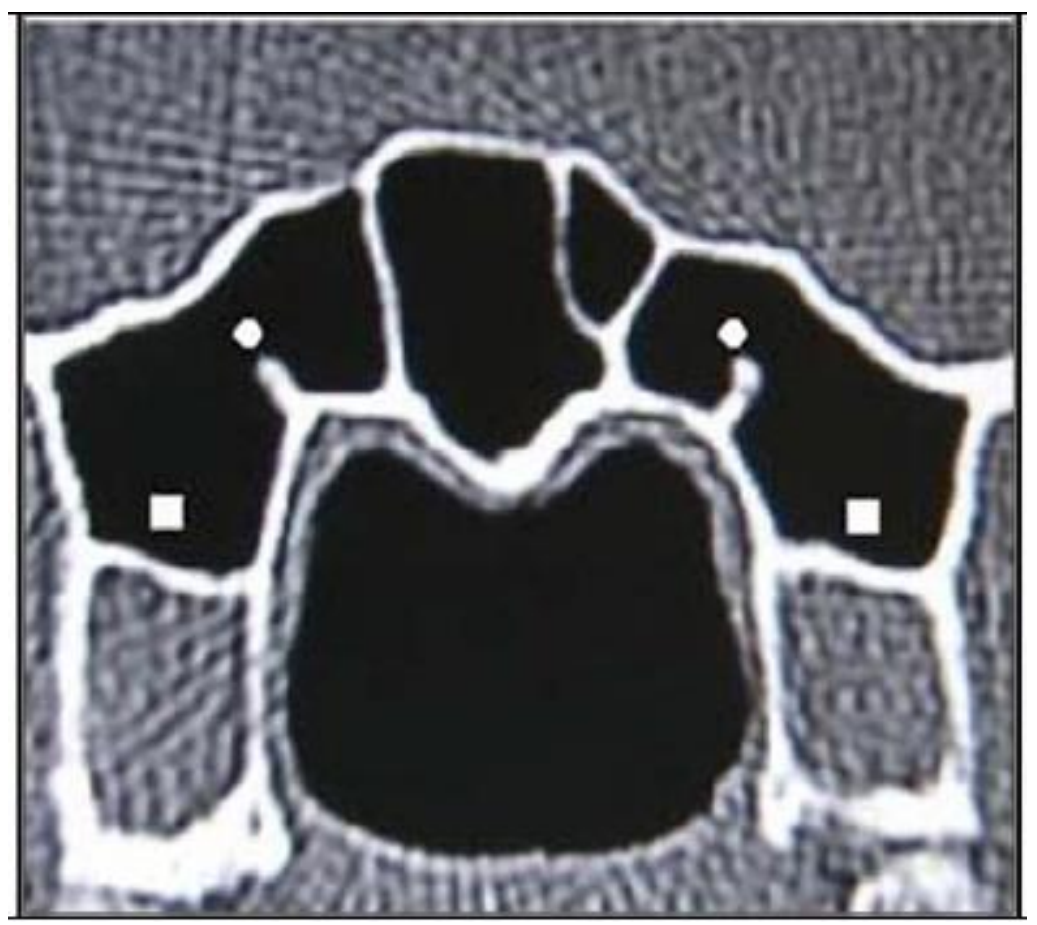

Figure (5): Coronal CT image showing pneumatization of pterygoid processes (squares), and protrusion of vidian canals (circles) 


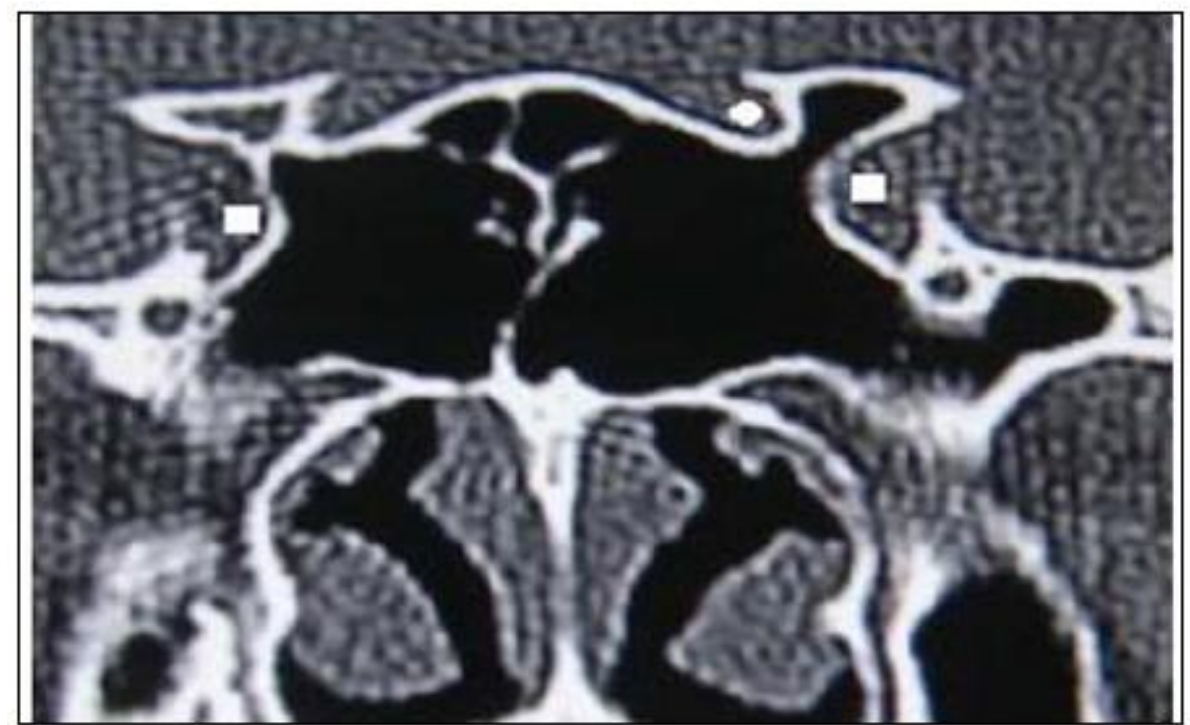

Figure (6): Coronal CT image showing protrusion of internal carotid arteries (squares), and protrusion of left optic nerve (circle)

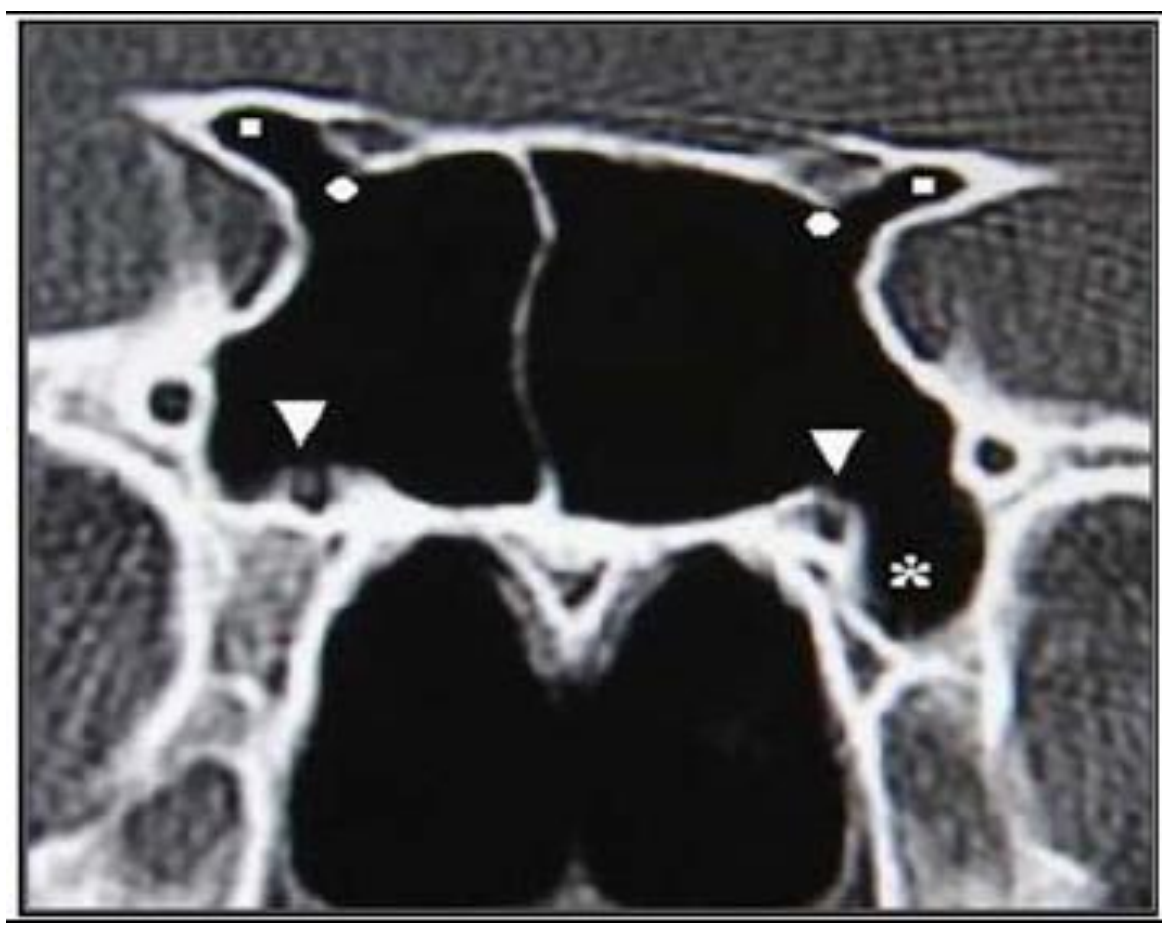

Figure (7): Coronal CT image showing pneumatization of anterior clinoid processes (squares), protrusion and dehiscence of optic nerves (circles), protrusion and dehiscence of vidian nerves (arrowheads), and pneumatization of left pterygoid process (asterisk)

\section{DISCUSSION}

Endoscopic sinus surgery (ESS), which gains importance each passing day, is a method safely used in the treatment of paranasal sinus diseases. Frequent and broad application of ESS in parallel with experience makes it imperative to know the anatomy and the existing pathology 
very well before surgery (Güldner et al., 2012).

In spite of the complex anatomy and important surgical relationships of the sphenoid sinus, to our knowledge, only a few relevant studies have been reported from. The aims of the study were to study the important structures in the sphenoid sinus and find anatomical variations in this area to guide otorhinolaryngologists and neurosurgeons to avoid injury of the vital structures during their procedures aiming to safe and complete eradication of the pathology.

Pterygoid process pneumatization is recognized if it extends beyond a horizontal plane crossing the vidian canal. We found pneumatization of PP in $30 \%$ of patients. The association between anomalies in the sphenoid sinus area in paranasal sinuses computed tomography (PNS-CT) and pathological findings and determined variations of sphenoid sinus. Pterygoid process pneumatization was observed. We found pneumatization of ACP in $16 \%$ of patients. It was observed anterior clinoid process pneumatization in a total of 85 sides (Turkdogan et al., 2017).

Radiological experience revealed that carefully tracing the course of the optic nerve and internal carotid artery seemed to underestimate the presence of protrusion. Therefore, as a rule, ipsilateral anterior clinoid process pneumatization was a good indicator of optic nerve and internal carotid artery protrusion.

We found pneumatization of GWS in $30 \%$ of patients. It was found encountered pneumatization of the greater wing of sphenoid of $20 \%$ of cases (Hewaidi and Omami, 2010).
We found protrusion of ICA in $40 \%$ of patients, and dehiscence of it in $30 \%$ of patients. Mamatha et al. (2010) evaluated the incidence of the different anatomical variations of the sphenoid sinus that are relevant to trans-sphenoid pituitary surgery. ICA produced a definite bulge in the supero-lateral wall of the sinus in $50 \%$ of patients, of which $15 \%$ were bilateral, $30 \%$ were left sided, and one on right side. A definite dehiscence of the bony wall was seen in $45 \%$ cases, of which $15 \%$ were bilateral, $30 \%$ were on the left, and one on the right. It was observed ICA protrusion in a total of 51 sides (Turkdogan et al., 2017).

We found protrusion of $\mathrm{ON}$ in $36 \%$ of patients and dehiscence of it in $31 \%$ of patients. It found the protrusion of the optic nerve in $35.7 \%$ of patients (Hewaidi and Omami, 2010). Dehiscence of the bony wall of the optic canal was observed $30.7 \%$ of patients.

We found protrusion of $\mathrm{MN}$ in $25 \%$ of patients and dehiscence of it in $14 \%$ of patients. It was encountered the protrusion of the maxillary canal (foramen rotundum) in $24.3 \%$ of patients. Dehiscence of the bony wall of the maxillary canal was seen in $13 \%$ of patients (Hewaidi and Omami, 2010).

We found protrusion of $\mathrm{VN}$ in $28 \%$ of patients, and dehiscence of it in $37 \%$ of patients. It was observed vidian canal protrusion (Turkdogan et al., 2017).

In our study, there was a significant association between ACP pneumatization and ICA protrusion, ACP pneumatization and $\mathrm{ON}$ protrusion, $\mathrm{PP}$ pneumatization and VN protrusion, and GWS pneumatization and $\mathrm{MN}$ protrusion. 
The septation pattern of the sphenoid sinus in a high-resolution computed tomography (CT) database was characterized. It was concluded that dimensions and septation patterns of the sphenoid sinus from 90 high-resolution CT images of patients without sinus pathology were analyzed. Pneumatization was described according to previously reported studies. The use of thin-cut image-guided radiographs in patients without skull base pathology and sphenoid rhinosinusitis allows for a complete categorization of sphenoid sinus anatomy without pathologic distortion. The data showed great variability of sphenoid sinus anatomy and suggest careful preoperative evaluation when approaching the skull base through an endonasal transsphenoidal corridor (Wiebracht and Zimmer, 2014).

The importance of PNS-CT in terms of determining anatomic variations before ESS and predicting possible complications during surgery has been emphasized once more. As sphenoid sinus pneumatization increased, the projection of neighbouring vein and nerve structures into the sinus was found to increase as well (Turkdogan et al., 2017).

\section{CONCLUSION}

The anatomical variations of the sphenoid sinus were remarkably common. Prevalence of protrusion and dehiscence of the internal carotid artery and optic nerve were high. The internal carotid artery and optic nerve may not be well protected and thus could be damaged during endoscopic sphenoid surgery. Protrusion of the internal carotid artery andor optic nerve was strongly associated with ipsilateral pneumatization of the anterior clinoid process. Protrusion and dehiscence of the maxillary nerve were less common. Protrusion of the vidian canal into the sinus cavity was strongly associated with pneumatization of the pterygoid process.

Coronal CT screening should be used in the pre-surgical evaluation of patients under consideration of endoscopic sphenoid sinus surgery to minimize perioperative neural and vascular injury.

\section{REFERENCES}

1. Davoodi M, Saki N, Saki G and Kumar V. (2011): Anatomical variations of neurovascular structures adjacent sphenoid sinus by using CT scan. Pak J Biol Sci., 129(6): 522-5.

2. DeLano MC, Fun FY and Zinreich SJ. (2010): Relationship of the optic nerve to the posterior paranasal sinuses: A CT anatomic study. AJNR Am J Neuroradiol., 17: 669-675.

3. Güldner C, Pistorius SM, Diogo I, Bien S, Sesterhenn $A$ and Werner JA. (2012): Analysis of pneumatization and neurovascular structures ofhe sphenoid sinus using cone-beam tomography (CBT). Acta Radiol., 53(2): 214-9.

4. Hewaidi GH and Omami GM. (2010): Anatomic variation of sphenoid sinus and related structures in Libyan population: CT scan study. Libyan J Med., 128-133.

5. Kim JY, Kim HJ, Kim CH, Lee JG and Yoon JH. (2010): Optic 
nerve injury secondary to endoscopic sinus surgery: an analysis of three cases. Yonsei Medical Journal, 46(2):300-4.

6. Mamatha H, Saraswathi $G$ and Prasanna LC. (2010): Variations of sphenoid sinus and their impact on related neurovascular structures. Current Neurobiology, 1(2): 121-124.

7. Tekiner $\mathrm{H}$, Acer $\mathrm{N}$ and Kelestimur F (2015): Sella turcica: An anatomical, endocrinological, and historical perspective. Pituitary, 18(4):575578

8. Turkdogan FT, Turkdogan KA, Dogan M and Atalar M. (2017): Assessment of sphenoid sinus related anatomic variations with computed tomography. Pan African Medical Journal, 27: 10914.

9. Wiebracht ND and Zimmer LA (2014): Complex anatomy of the sphenoid sinus: A radiographic study and literature review. J Neurol Surg B., 75: 378-382. 
در اسة تصوير الجيب الوتدي و التخيرات التشريحية للأعصاب و الأو عية الدموية المتعلقة بهابه

محمد عبد القادر الزنفلي, أحمد محمود خليفه, عادل عز الدين عمر, مختار رجب الداله رمضان*، أيمن عبد العزيز الشهالي, يحيى محمد داوود الهمد

قسمي جراحة الأنف والأنن والحنجرة والأشعة التثخيصةث*, كلية الطب, جامعة الأزهر

E-mail: mohamed_elzanfaly2011@gmail.com

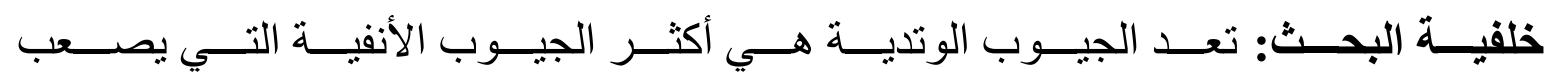

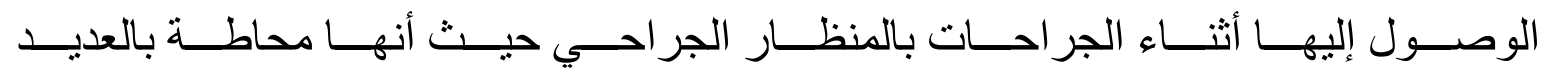

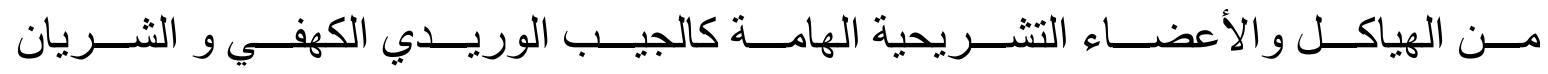

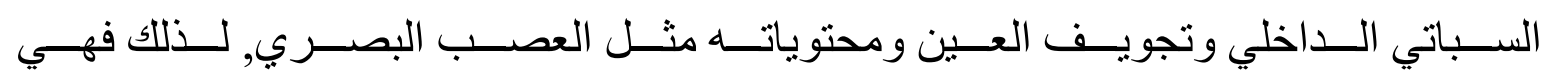

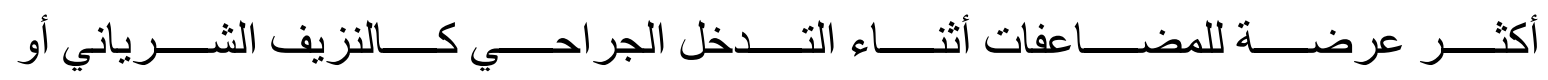
إصابة العصب البصري وفقدان البصر أو تلف عضلات العين.

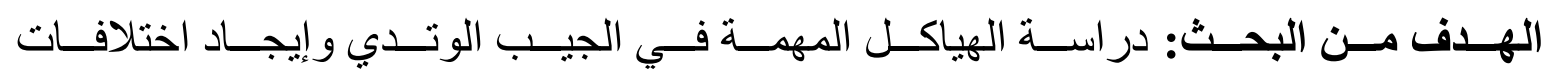

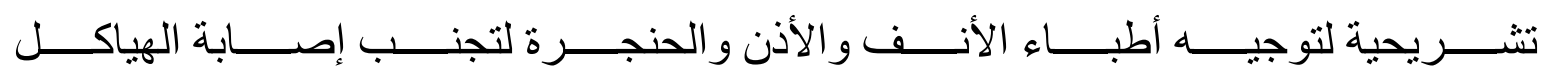

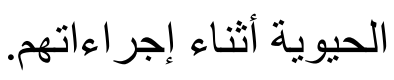

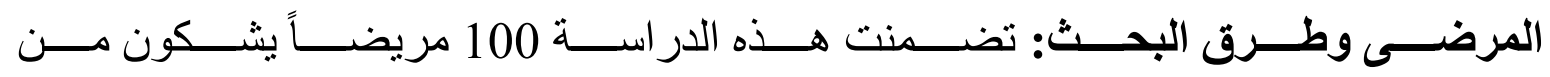

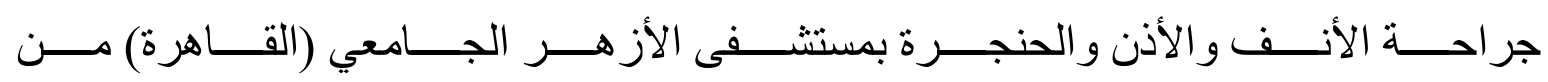

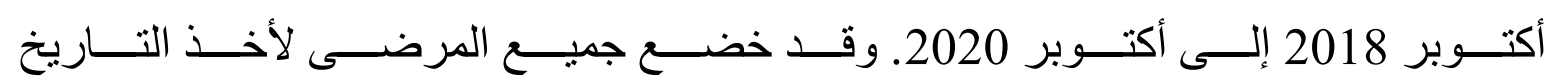

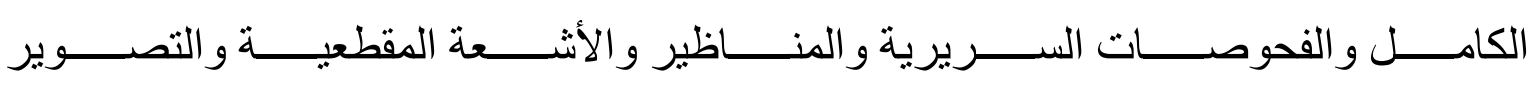
بالرنين المغناطيسي.

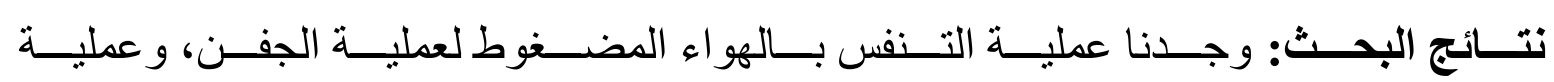

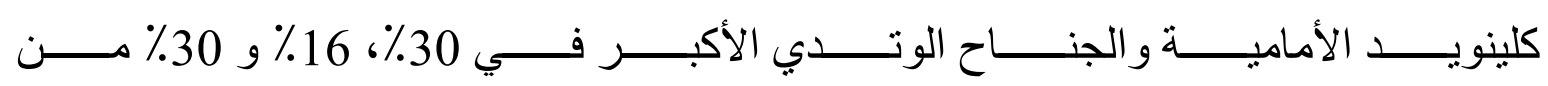

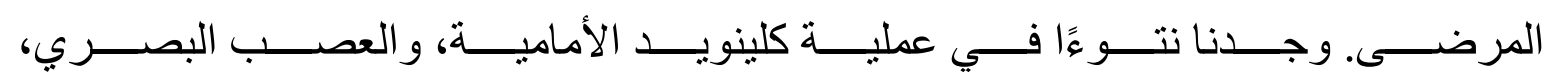

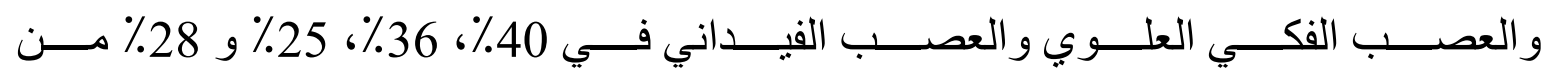




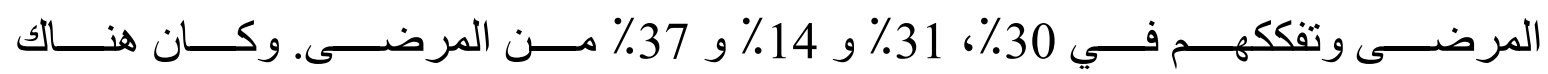

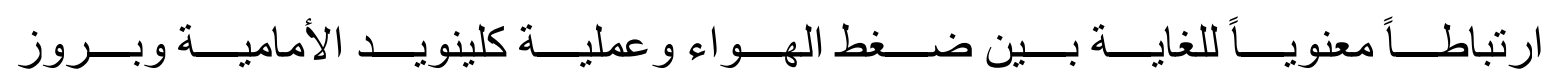

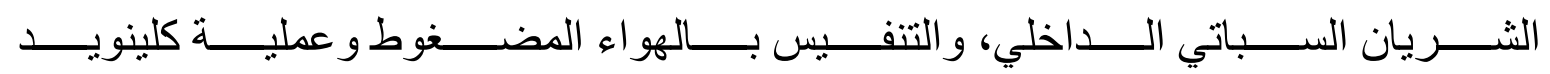

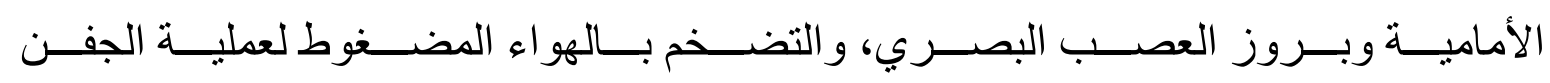

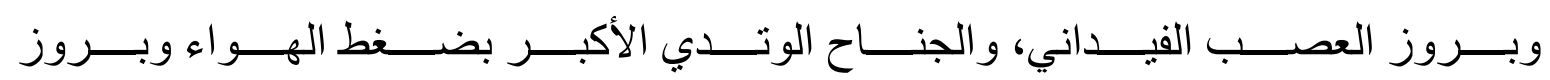

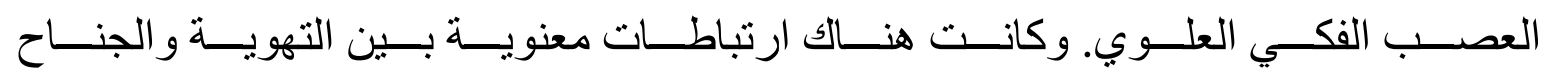

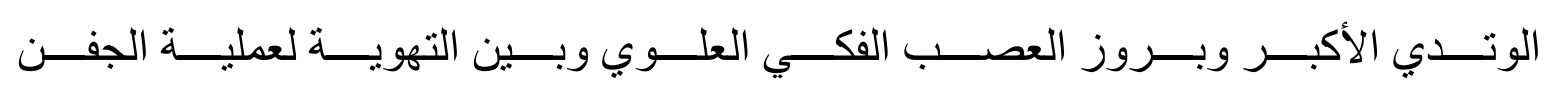
وبروز العصب الفيداني.

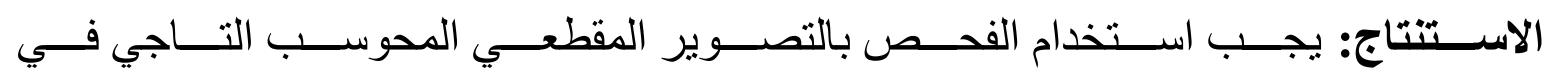

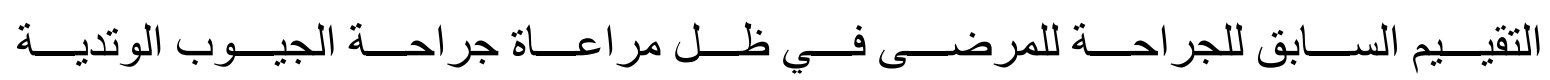
بالمنظار لتقليل الإصابة العصبية والأو عية الدموية المحيطة بالجر احة.

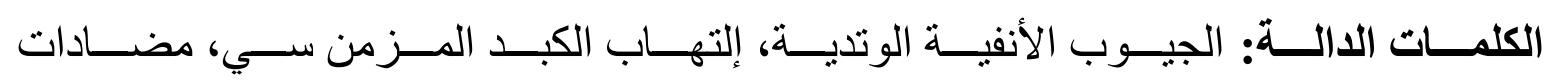
الفيروسات ذات المفعول المباثر. 